\title{
Shared Decision Making and the Experience of Partnership in Primary Care
}

\author{
George W. Saba, $P b D^{1,2,3}$ \\ Sabrina T. Wong, RN, $P b D^{3,4}$ \\ Dean Schillinger, $M D^{3,5}$ \\ Alicia Fernandez, $M D^{3,5}$ \\ Carol P. Somkin, $P h D^{3,6}$ \\ Clifford C. Wilson, BA ${ }^{3,5}$ \\ Kevin Grumbach, $M D^{1,2,3}$ \\ 'Department of Family and Community \\ Medicine, University of California, \\ San Francisco, Calif \\ ${ }^{2}$ Department of Family and Community \\ Medicine, San Francisco General Hospital, \\ San Francisco, Calif \\ ${ }^{3}$ Medical Effectiveness Research Center \\ for Diverse Populations, University of \\ California, San Francisco, Calif \\ ${ }^{4}$ School of Nursing, University of British \\ Columbia, Vancouver, British Columbia \\ ${ }^{5}$ Department of Medicine, Division of \\ General Internal Medicine, San Francisco \\ General Hospital, San Francisco, Calif \\ ${ }^{6}$ Division of Research, Kaiser Permanente, \\ Oakland, Calif
}

Conflicts of interest: none reported

\section{CORRESPONDING AUTHOR}

George W. Saba, PhD

Department of Family and Community Medicine

University of California, San Francisco

San Francisco General Hospital

Bldg 80, Ward 83

1001 Potrero Ave

San Francisco, CA 94110

gsaba@medsch.ucsf.edu

\begin{abstract}
PURPOSE Communication has been researched either as a set of behaviors or as a facet of the patient-physician relationship, often leading to conflicting results. To determine the relationship between these perspectives, we examined shared decision making (SDM) and the subjective experience of partnership for patients and physicians in primary care.
\end{abstract}

METHODS From a convenience sample of experienced primary care physicians in 3 clinics, we recruited a stratified sample of 18 English- or Spanish-speaking patients. Direct observation of visits was followed by videotape-triggered stimulated recall sessions with patients and physicians. We coded decision moments for objective evidence of SDM, using a structured instrument. We classified patients' and physicians' subjective experience of partnership as positive or negative by a consensus analysis of stimulated recall sessions. We combined results from these 2 analyses to generate 4 archetypes of engagements and used grounded theory to identify themes associated with each archetype.

RESULTS The 18 visits yielded 125 decisions, 62 (50\%) of which demonstrated SDM. Eighty-two decisions were discussed in stimulated recall and available for combined analysis, resulting in 4 archetypes of engagement in decision making: full engagement (SDM present, subjective experience positive)-22\%; simulated engagement (SDM present, subjective experience negative)-38\%; assumed engagement (SDM absent, subjective experience positive)-21\%; and nonengagement (SDM absent, subjective experience negative)-19\%. Thematic analysis revealed that both relationship factors (eg, trust, power) and communication behavior influenced subjective experience of partnership.

CONCLUSIONS Combining direct observation and assessment of the subjective experience of partnership suggests that communication behavior does not ensure an experience of collaboration, and a positive subjective experience of partnership does not reflect full communication. Attempts to enhance patient-physician partnership must attend to both effective communication style and affective relationship dynamics.

Ann Fam Med 2006;4:54-62: DOI: 10.1370/afm.393

\section{INTRODUCTION}

C ommunication in medical encounters has been conceptualized from at least 2 different perspectives. ${ }^{1}$ Through one lens, communication consists of a set of skills and behaviors that can be directly observed, delineated, and taught. Through a different lens, communication reflects the perceptions patients and physicians have of their relationship, best understood by gaining insight into the subjective experiences of the participants. Researchers have traditionally used one or the other lens to examine patient-physician interactions, often leading to conflicting results. ${ }^{1}$

Research exploring shared decision making (SDM) illustrates the challenges posed by using different perspectives. SDM, promoted as an ideal and ethical model of patient-physician communication, consists of 
patients and physicians making decisions after openly exchanging information, exploring beliefs, and reaching explicit closure. ${ }^{2-7}$ Advocates of SDM believe it provides patients and physicians a better experience of the medical encounter than does either a paternalistic (physician-directed) or a consumerist (patientdirected) decision-making style. ${ }^{8}$ Some studies show SDM enhances patient satisfaction, improves patient adherence to medications, and results in better health outcomes. ${ }^{9-15}$ But research on the experience of SDM remains limited, and what literature exists reveals inconsistent findings.

Golin et a ${ }^{16}$ found patients were more satisfied with care when they believed their physicians facilitated their participation in diabetes care decisions. Yet, Mead et $\mathrm{al}^{17}$ found general practitioners' patient-centered behaviors, including elements of SDM, did not predict patients' satisfaction or self-efficacy. Evaluation of an intervention to train practitioners in SDM techniques found that although training altered physicians' communication behavior, it had little effect on patients' satisfaction or sense of involvement in treatment decisions. ${ }^{18}$ A recent study found that white and African American patients rated the participatory style of their physician higher in racially concordant visits; however, objective measures of patient-centered verbal behavior did not differ significantly between racially concordant and discordant visits. ${ }^{19}$

Understanding the relationship between communication skills, such as SDM, and subjective experience may require new research strategies. Zoppi and Epstein ${ }^{1}$ suggest that to better understand patient-physician communication, investigators should observe communication behaviors and concurrently gather participants' subjective experiences of the interaction. Agreeing with this perspective on the state of SDM and communication research, ${ }^{1-19}$ we used a mixed methods design, ${ }^{20}$ combining direct observation of primary care visits with a technique for capturing subjective experience to determine (1) how the communication behavior of SDM is related to patients' and physicians' subjective experience of partnership and (2) whether the combination of direct observation and experiential research yields novel insights into communication. Primary care visits, with their focus on complex decision making and long-term relationships, provide a rich opportunity for exploring these questions. We examined decision making among a population of low-income, predominantly minority patients, recognizing that the theoretical benefits of SDM take on additional importance in disadvantaged populations, who often report less trust, lower satisfaction, and less participation in medical encounters. ${ }^{21}$

\section{METHODS}

Study Design

From July 2002 to November 2003, we videotaped primary care visits and developed a structured instrument to assess observable aspects of patient-physician decision making. We used the same videotapes to explore the subjective experience of partnership of patients and physicians using stimulated recall.22-25 Stimulated recall uses prompts from the videotaped visit to elicit participants' subjective experience of an interaction, in a guided interview. We coded transcripts of the stimulated recall sessions for themes and the subjective experience of partnership for each decision. Finally, we combined the results from the coded clinical visits and stimulated recall sessions to generate a $2 \times 2$ matrix of patient-physician decision making and explored the implications of the resulting 4 archetypes.

\section{Participants and Procedures}

We recruited a convenience sample of experienced primary care physicians from 3 practices affiliated with a San Francisco public teaching hospital. Physicians were invited at faculty meetings to participate in a study on "communication in primary care visits." Volunteer physicians reviewed their patient lists for upcoming clinic sessions and identified their patients meeting eligibility criteria: (1) a diagnosis of diabetes, hypertension, or both (to enhance the likelihood a visit included clinical decisions); (2) English speaking, or Spanish speaking with a physician who spoke Spanish; and (3) at least 2 previous visits with the physician. We recruited patients in the waiting room (excluding only those who appeared to the research staff to be acutely ill, intoxicated, or psychotic). Using a stratified design to ensure racial/ethnic diversity, we recruited at least 3 patients from each of following racial/ethnic groups: African American, Asian, Latino, and white. We determined our sample size based on reaching theoretical saturation. All procedures were approved by the University of California, San Francisco, Institutional Review Board.

After obtaining informed consent and before the visit, we collected demographic information from patients and physicians using a questionnaire. We then videotaped the visits, and patients and physicians independently viewed the videotapes within 2 weeks in a stimulated recall session with a trained facilitator. Stimulated recall uses cues from a recorded interaction to stimulate the recall of underlying thought processes, feelings, or perceptions associated with particular events in the interaction. ${ }^{22-25}$ Facilitators instructed participants to stop the videotaped visit whenever they identified thoughts, feelings, and behaviors related to the decision-making process. We developed a semistructured interview guide based on the traditional 
stimulated recall method $\mathrm{d}^{23-25}$ and the literature on SDM. ${ }^{6,7,26-29}$ Facilitators probed both global relationship issues and specific decision moments, stopping the tape when appropriate. After the first 5 stimulated recall sessions with both physicians and patients, we reviewed this interview guide and decided to continue using it without modification. Four coinvestigators (GWS, AF, DS, STW) facilitated the stimulated recall sessions, following the same protocol and conducting them in either English or Spanish. The 3 Spanish interviews were conducted by a bilingual Latina investigator (AF). Stimulated recall sessions were videotaped.

Visits and stimulated recall sessions were transcribed and translated, if necessary, by a bilingual research associate. A second bilingual researcher compared transcripts with the original videotapes to ensure translation accuracy. Three visits and stimulated recall sessions required translation.

\section{Analysis}

Our unit of analysis was the decision moment, defined as a meaningful, observable event in the encounter that contained an implicit or explicit choice of action for the present or future (eg, "I think we should increase your blood pressure medication."). To analyze the data, the research team formed 2 coding groups, 1 for visits and 1 for stimulated recall sessions; the findings emerged through consensus within each group. Neither group discussed its findings with the other until they had completed the coding for each visit. We used NVivo 2.0 software $^{30}$ to store, organize, and retrieve data.

\section{Coding Communication Behavior}

On the basis of the work of Elwyn et $\mathrm{al}^{3,26,27}$ and Braddock et al, ${ }^{28,29}$ we identified 3 domains of behaviors common to the SDM process: (1) exchanging feelings and beliefs; $f_{i}$ (2) exchanging information about the disease, its diagnosis, and its treatment; and (3) reaching closure. We developed a coding framework for SDM consisting of 5 communication behavior categories: (1) offering beliefs, (2) eliciting beliefs, (3) offering information, (4) eliciting information, and (5) reaching closure (The coding instrument for direct observation of visits can be found in Supplemental Appendix 1,

available online-only at http://www.annfammed. org/cgi/content/full/4/1/54/DC1). One point was assigned for the presence of each behavior on the part of the patient and the physician, regardless of how many times it occurred (eg, offering beliefs several times), resulting in scores ranging from 0 to 10 . At least 2 team members independently coded the encounter, resolving the few scoring disagreements (less than 15\% of encounters coded) by consensus. We categorized decision moments that received at least 6 points, 1 of which included closure of the decision by the patient, as indicating the presence of SDM. Because prior studies on communication have suggested that the power dynamics implicit in the patient-physician relationship may make the outcome of a decision-making dialogue difficult to infer, ${ }^{2-7}$ we required that for SDM to be coded through direct observation as present, the patient needed to provide explicit closure. To ensure that the choice of 6 points as indicating SDM did not skew the analysis, we performed a sensitivity analysis using different cutoff points to identify the change in decision moments considered SDM.

\section{Capturing Subjective Experience}

We used a consensus process to classify the patient's and physician's description of each decision moment as reflecting either a subjectively positive (collaborative) or a subjectively negative (noncollaborative) experience of partnering. An example of a negative experience is the acknowledgment in the stimulated recall of withholding important information during the clinic visit (eg, "I did not tell the doctor I was not taking the medicine," or "I am frustrated with this patient, but have not told him."). If either participant described the experience of a decision moment in negative terms, we classified the decision moment as noncollaborative.

Team members represented different disciplines (medicine, nursing, psychology, and sociology) and had had graduate training in cross-cultural communication. Each member individually reviewed data from the stimulated recall sessions and identified themes using grounded theory. ${ }^{31}$ We conducted the thematic analysis through an iterative consensus process as a group, using triangulation techniques to validate the key findings. ${ }^{32-36}$

Combining the Objective and Subjective Data Sets After coding visits and stimulated recall sessions, the data from direct observation (ie, objective data set), with each decision moment categorized as SDM present or absent, were combined with the data from the stimulated recall sessions (ie, subjective data set), with sessions categorized as negative or positive. This process created a $2 \times 2$ matrix consisting of 4 archetypes of engagement in decision making (Figure 1).

\section{RESULTS}

Ten physicians volunteered to participate; each had a minimum of 1 and a maximum of 3 visits included in the study. Forty of 43 patients approached for recruitment were eligible to participate ; of these patients, 17 declined. Of the remaining 23 patients, 22 had their clinic visits videotaped 18 patients completed their stimulated recall sessions and constituted our study 


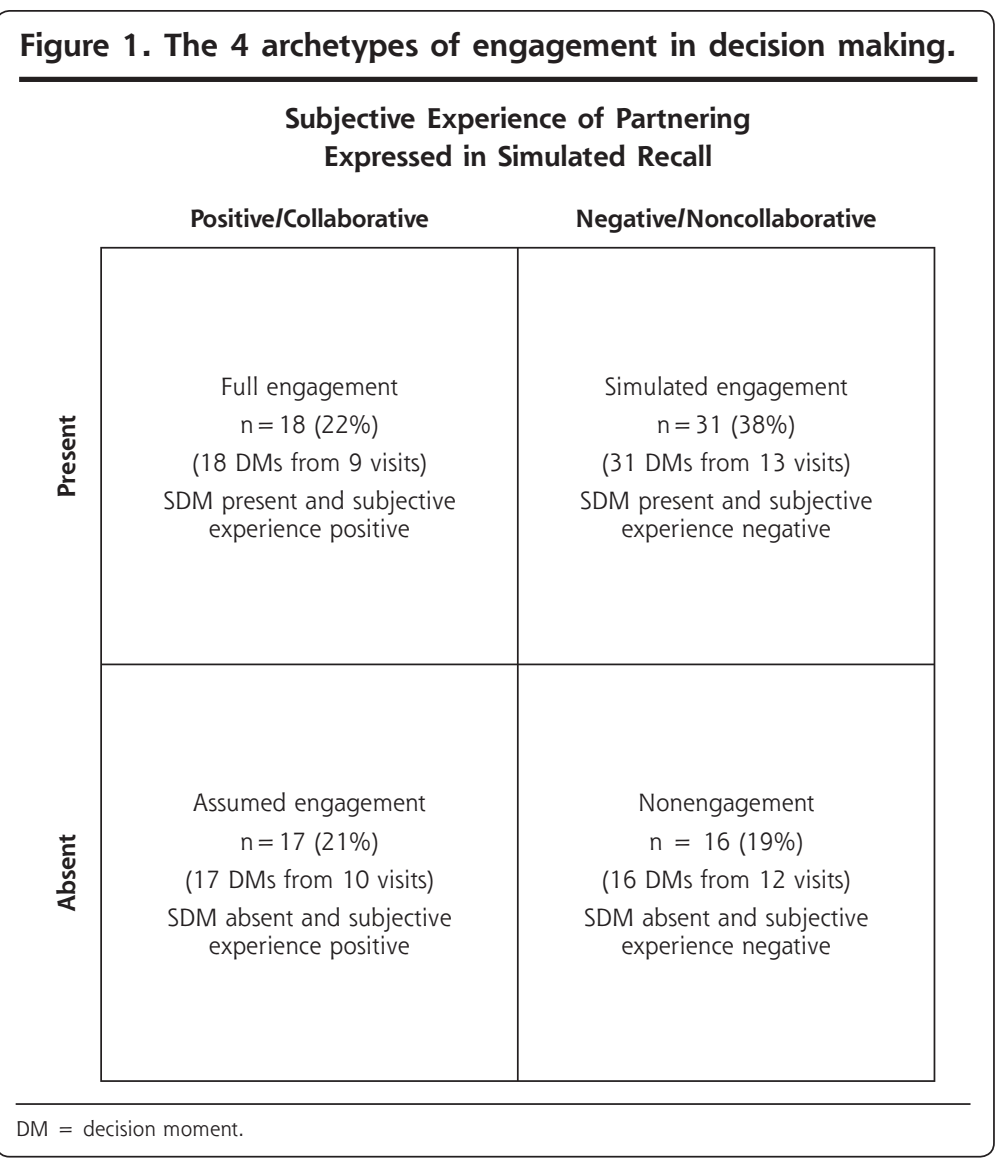

Figure 1 presents the distribution among archetypes of the 82 decision moments available for the combined analysis. Each archetype was represented by at least $19 \%$ of the decision moments. When the cutoff point for the presence of SDM was raised to $7 / 10$, the distribution across archetypes changed minimally-full engagement, $18 \%$; simulated engagement, $28 \%$; assumed engagement, $24 \%$; nonengagement, 30\%. When the cutoff point was lowered to $5 / 10$, the distribution changed more substantially-to $31 \%$, $41 \%, 12 \%$, and $16 \%$, respectively. A second sensitivity analysis was conducted to determine whether physician behaviors dominated the SDM scores; only 3 out of 49 decision moments scored as SDM present did not have at least 3 component behaviors contributed by patients.

In 47 decision moments, at least 1 of the participants reported a negative experience (Table 1). Both patients and physicians reported their experience as negative in 8 of these decision moments, while in 25 , physicians alone experienced the moment as negative, and in 14, patients alone experienced the moment as negative. Table 3 displays the distribution of the archetypes within visits

population. Table 1 shows the characteristics of the patients, the physicians, and their relationship.

Analysis revealed 125 decision moments, with a mean of 7 decision moments per visit (range, 3-11). Table 2 displays the content of these decision moments and the distribution of SDM scores. Decisions often concerned medication (33\%) or self-management and lifestyle modifications (22\%). One half of the decision moments had an SDM score of 6 or greater. Eighty-two $(66 \%)$ of the decision moments were commented on by participants in the stimulated recall sessions and therefore were available for the analysis that combined both direct observation and stimulated recall scores.

Combining the direct observation and stimulated recall analyses revealed 4 archetypes of engagement in decision making that we labeled as follows: (1) full engagement (SDM present, subjective experience positive), (2) simulated engagement (SDM present, subjective experience negative), (3) assumed engagement (SDM absent, subjective experience positive), and (4) nonengagement (SDM absent, subjective experience negative). These labels are not meant to imply a value judgment; rather, they denote the conceptual alignment of 2 dimensions of patient-physician communication: SDM behavior and participants' subjective experience.

\section{Archetypes of Engagement in Decision Making}

Below we provide examples of the 4 archetypes and dominant themes. Additional examples are shown in Table 4, and additional illustrative quotes are provided in Supplemental Appendix 2, available online-only at http://www.annfammed.org/cgi/content/full/ 4/1/54/DC1.

\section{Full Engagement}

Thematic analysis revealed physicians and patients in full engagement decision moments (1) felt listened to and understood, (2) trusted each other, (3) expressed differences of opinion, (4) negotiated decisions, and (5) agreed to disagree. In a decision moment involving diagnostic testing options (stress test or catheterization) for a patient with worsening angina, the discussion scored 10/10 for SDM. Stimulated recall revealed both participants experienced the decision making as positive.

Patient: "I asked her for her opinion; she's the doctor. That's what she decided. Or that's what we decided." 


\begin{tabular}{|c|c|}
\hline Characteristics & No. (Range) \\
\hline \multicolumn{2}{|l|}{ Patient characteristics $(n=18)$} \\
\hline Age, years, mean & $62(42-78)$ \\
\hline \multicolumn{2}{|l|}{ Sex } \\
\hline Female & 7 \\
\hline Male & 11 \\
\hline \multicolumn{2}{|l|}{ Race/ethnicity, self-reported } \\
\hline African American & 7 \\
\hline Asian & 3 \\
\hline Latino & 5 \\
\hline White & 3 \\
\hline Education, years, mean & $10(0-18)$ \\
\hline \multicolumn{2}{|l|}{ Language spoken } \\
\hline English & 15 \\
\hline Spanish & 3 \\
\hline \multicolumn{2}{|c|}{ Physician characteristics $(n=10)$} \\
\hline Age, years, mean & $44.6(37-60)$ \\
\hline \multicolumn{2}{|l|}{ Sex } \\
\hline Female & 6 \\
\hline Male & 4 \\
\hline \multicolumn{2}{|l|}{ Race/ethnicity, self-reported } \\
\hline African American & 1 \\
\hline Asian & 1 \\
\hline Latino & 1 \\
\hline White & 7 \\
\hline Time in practice, years, mean & $14(8-40)$ \\
\hline \multicolumn{2}{|c|}{ Patient-physician relationship $(\mathrm{n}=18)$} \\
\hline Continuity, years, mean & $6(0.5-15)$ \\
\hline
\end{tabular}

Physician: "I gave her some space ${ }_{i}$ I think if she had any strong thoughts against catheterization, she would have said it" [Visit 20].

\section{Simulated Engagement}

Analysis revealed a number of themes in simulated engagement decision moments. Participants (1) did not disclose relevant clinical information, (2) tended not to display emotional reactions, (3) made assumptions, without checking their accuracy, about what the other person thought or how he/she would act if told the truth, and (4) feared negative judgment and being disrespected. In a decision moment about changing a patient's antihypertensive medication, a considerable exchange of information occurred, scoring 9/10 on SDM, including apparent closure. But while the physician reported the decision moment as positive, the patient reported it as negative. In this instance, the patient did not tell the physician how he felt about the care received.

Patient: "He isn't doing anything for me. I've been swollen up like this [in my legs] for almost a year; he hasn't done anything. He doesn't even look at it. He either doesn't get it or doesn't care."
Table 2. Characteristics of the Decision Moments

\begin{tabular}{lc}
\hline Characteristic & $\begin{array}{c}\text { Decision } \\
\text { Moments } \\
\text { No. (\%) }\end{array}$ \\
\hline Topic & \\
Medication & $41(33)$ \\
Self-management and lifestyle & $28(22)$ \\
Referrals & $24(19)$ \\
Tests & $20(16)$ \\
Other treatments & $12(10)$ \\
Total & $125(100)$ \\
Distribution of SDM scores & \\
0-2 & $25(20)$ \\
$3-5$ & $38(30)$ \\
6-8 & $43(35)$ \\
$9-10$ & $19(15)$ \\
Total & $125(100)$ \\
Distribution of subjective & \\
experiences* & \\
Positive & \\
Negative & $35(43)$ \\
Total & $47(57)$ \\
Nature of the negative & $82(100)$ \\
subjective experiences & \\
Both physician and patient negative & \\
Only physician negative & \\
Only patient negative & $14(30)$ \\
Total & $47(100)$ \\
\hline SDM = shared decision making. & \\
*Among the subset of decision moments available for combined analysis. \\
\end{tabular}

Table 3. Distribution of Archetypes Within Visits

\begin{tabular}{lc}
\hline Variation of Archetypes Within a Visit & $\begin{array}{c}\text { No. of Visits } \\
(\mathbf{n}=\mathbf{1 8})\end{array}$ \\
\hline $\begin{array}{l}\text { All decision moments in visit coded as the same } \\
\text { archetype (eg, all decision moments in Visit } 23\end{array}$ & 2 \\
were coded as simulated engagement) \\
$\begin{array}{l}\text { Majority (60\%-90\%) of the decision moments } \\
\text { in visit coded as the same archetype }\end{array}$ \\
$\begin{array}{l}\text { No majority of decision moments in visit coded } \\
\text { as the same archetype }\end{array}$ \\
\hline
\end{tabular}

Physician: "He understands the problem... we are on the same wavelength" [Visit 19].

\section{Assumed Engagement}

Thematic analysis of assumed engagement decision moments revealed that participants (1) frequently made assumptions about each other's understanding of the situation and why the other acted in a certain way, (2) did not check the accuracy of these assumptions, and (3) were confident they were "on the same wavelength." In one visit, during a discussion about the appropriate insulin dose, the SDM score was 5/10, 
Table 4. Communication Behaviors and Relationship Themes Characteristic of Archetypes of Engagement in Decision Making

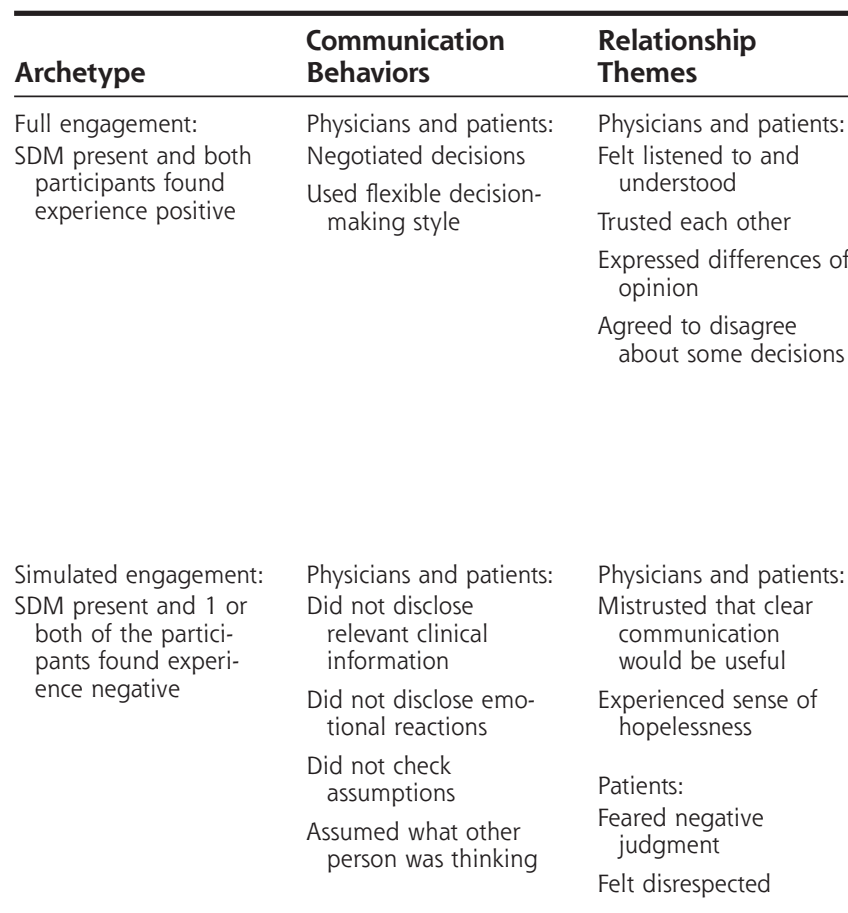

Assumed engagement: SDM absent and both participants found experience positive

Nonengagement: SDM absent and 1 or both participants found experience negative
Physicians and patients: Assumed understanding each other and why other person acted the way hel she did

Did not check out assumptions Trusted each other Felt listened to and understood

Were confident they were on the same wavelength
Physicians and patients:

\section{Clinical Example}

Patient requested an anxiolytic medication to cope with a divorce. Ensuing conversation included all 10 of the elements of SDM, and stimulated recall revealed a mutually positive experience. [Visit 23]

Patient: "She trusts me. She believes I wouldn't abuse it. She believes in me, and that's a big thing. I would never do that to her anyway. Some addicts would play their doctors; I've never played her like that. She really cares for me. We are pretty straightforward with each other; I always tell her the truth. She's never given up on me."

Physician: "She's going through a big thing [leaving her husband]. She's more paranoid about getting addicted again than I am; so I decided to give it [the Valium]. I didn't want her to think I don't trust her. Thirty Valium is not that big of a deal to me in our relationship or in her care."

Physician and patient considered how weight loss might improve the patient's diabetes. The SDM score was relatively high $(6 / 10)$, yet both the patient and the physician found the experience negative. Here, the patient did not disclose relevant clinical information, assuming that the physician would be angry at her if she revealed this information. [Visit 37]

Patient: "I haven't told him [the physician] I am eating pastries... I don't want to disappoint him and run the risk that he says I've done a lot for you and you are not doing your part.... I can't afford to lose him. I'm not being honest."

Physician: who chose to not display his emotions about a challenging situation, saying, "Talking about weight reduction is another big topic, and although important, it's not a priority issue here. I had other important issues to talk about, so to talk about another nonpressing matter without a satisfactory conclusion is frustrating. My vision of her is a lot of loose ends that are just kept loose."

Patient requested medication to help her sleep. SDM did not occur (score $=1 / 10$ ), but both the physician and patient found the experience positive. In this situation, the patient had an inaccurate assumption about why her physician acted a certain way. [Visit 12]

Patient: "He didn't just give me stronger medicine or say, 'Well, I think we should increase your dose, or we should do this.' He didn't go there. That makes me feel like he's concerned about me medical-wise and pain-wise, because he's not going just take my say-so and give me something."

Physician: "There wasn't time at the end, so I wasn't going to get into the sleep issue with her." The physician expresses satisfaction in being able to keep the discussion during the visit focused on what he considered more pressing issues.

Physicians and patients:

Did not disclose relevant clinical information

Did not disclose emotional reactions

Did not check assumptions

Assumed what other person was thinking

Assumed how other person would respond if told the truth
Physicians and patients: Mistrusted that clear communication would be useful

Experienced sense of hopelessness

Patients:

Feared negative judgment

Felt disrespected
A decision moment that focused on adherence to dietary restrictions for a diabetic patient had low SDM (score $=4 / 10$ ), and both partners had a negative experience. The patient's stimulated recall revealed that he did not disclose relevant clinical information and believed his views would be discounted by his physician. The physician's stimulated recall revealed his feeling of hopelessness in providing care [Visit 8].

Patient: (commenting on the physician's instruction not to eat flan and to throw out unwanted desserts) "Back in the Philippines, my parents said not to waste food and throw it away. I have relatives who are physicians who tell me not to worry too much about my diet. They know it's hard to have diabetes and say it's okay to have a beer, a light beer, and relax. I know my doctor is concerned about my health, so I don't tell him. You want to enjoy your life. If I tell him, he will just tell me what will happen to my body."

Physician: "He's never been adherent to a diabetic diet, and here he is obviously blatant about not being adherent. I was trying to plant a seed, but I have some frustration and a sense of almost futility with this patient."

SDM = shared decision making 
yet both the patient and physician had a positive experience.

Patient: "If I don't understand or didn't want to do it, I could call her, I can talk to her about anything."

Physician: "If she didn't understand what I wanted her to do, she would clarify it ... to make sure if she wasn't following it" [Visit 15].

\section{Nonengagement}

Thematic analysis of nonengagement decision moments revealed that (1) participants neither disclosed relevant clinical information nor expressed strong negative feelings, (2) patients feared negative judgments or consequences of disclosure, (3) patients felt disrespected or discounted, and (4) participants held a mutual distrust and sense of hopelessness. In a discussion about a patient's adherence to blood pressure medication, the SDM score was $2 / 10$; the patient found the experience negative and the physician found it positive. The stimulated recall sessions revealed that the patient had not disclosed relevant clinical information because of fears of negative judgment by the physician. The physician perceived a trusting relationship.

Patient: "So that's where I wasn't being truthful.... I took a lesser dose, took matters into my hands. But didn't tell him.... Doctors represent your parents. You don't want to destroy the trust."

Physician: "We have a pretty comfortable relationship. I trust he would tell me if he wasn't taking his medication" [Visit 11].

\section{DISCUSSION}

Communication in the patient-physician encounter has been viewed from 2 different perspectives. From one perspective, communication is a set of skills and behaviors that can be objectively observed. From the other perspective, it reflects the subjective experience of the patient-physician relationship. Our study used 2 methodologic lenses to examine the relationship between these perspectives. We combined the outsider's objective (etic) perspective through direct observation with the insider's subjective (emic) perspective through stimulated recall to enrich our understanding of patientphysician communication. ${ }^{37}$ These lenses created images of communication that are not always aligned, an observation that illuminates prior conflicting results in SDM research. In many $(41 \%)$ of the decision moments, agreement existed between the subjective perception of the participants and the objective ratings of SDM behaviors. This alignment occurred when participants experienced partnership and SDM was present (full engagement) and also when they experienced a lack of partnership and SDM was absent (nonengage- ment). But for the majority (59\%) of decision moments, communication behaviors and subjective experience were not aligned. Simulated engagement was common (38\% of decision moments). In this archetype, patients and physicians exchanged information and beliefs and appeared to make joint decisions; ${ }_{i}$ however, their relationship was characterized by mistrust, withholding of crucial information, or mutual frustration. Assumed engagement was also common $(21 \%$ of decision moments), with patients and physicians experiencing collaboration in their decision making despite a limited amount of explicit communication. Patterns of engagement often varied across decisions within a visit.

What do these findings tell us about communication in primary care? Communication is more complex than a set of communication behaviors. In simulated engagement, communication can "look good," but when it does not also "feel good," important information is often being withheld, and apparent agreement about a care plan may belie different intentions. Although our study found that SDM behavior is common, representing more than one half of decision making, it is nearly as likely to be associated with a negative subjective experience as a positive one. This finding has important implications for medical education and clinical care. A purely behavioral model for teaching communication skills appears inadequate. Without attention to affective aspects of the relationship, physicians and patients may find themselves going through the motions of SDM behavior without achieving satisfactory clinical outcomes. On the other hand, purely relational models of communication may also fail to capture important elements of decision making. In assumed engagement, just because it "feels good" does not mean participants exchange important information about options or beliefs. When working with patients who clinically are doing poorly, physicians already engaging in SDM may consider addressing relational issues (eg, asking patients how they feel about the decision-making process, giving patients permission to reveal any concerns or disagreements about the decision, revealing their own views about the process of decision making). Conversely, if the relationship feels collaborative, physicians may consider engaging in more SDM communication behavior (eg, eliciting and offering more information, feelings, and beliefs; reaching explicit closure).

Our findings may shed light on the inconsistent results of previous studies of SDM. In the studies by Mead et a $\mathrm{l}^{17}$ and Cooper et $\mathrm{al},{ }_{1}^{19}$ direct observation scores for elements of SDM, such as participatory communication, did not predict patients' ratings of their satisfaction with their physician or their subjective ratings of the physicians' collaborative style. Our results support the view that patients factor in the "affective 
dimension of interpersonal rapport,"19 as well as the physician's communication behavior, when making these judgments.

It is possible that a multidimensional view including affective and behavioral components of decision making may predict patients' clinical outcomes. One could hypothesize that full engagement would lead to better health outcomes, whereas nonengagement would not. More intriguing, perhaps, is the question of what happens when behavior and subjective experience are discordant, such as in assumed engagement. Is assumed engagement an efficient and convenient decision-making shortcut in the context of collaborative long-term relationships, or does it represent a missed opportunity for better communication and thus, perhaps, improved care?

In addition to not examining clinical outcomes, our study has several limitations. We cannot discern whether the patient-physician communication behaviors we observed shaped the experience of collaboration, or whether prior attitudes about the relationship determined the communication behaviors. Either explanation is possible, as is the notion that each shapes the other. Study visits may differ from other visits in primary care: the physician participants volunteered for this study and may differ from the overall population of primary care physicians, and videotaping the visits may have influenced participants' behavior. Patients, too, were volunteers, with a participation rate of $57 \%$, and they may have differed in important and unknown ways from other patients. The sample consisted of an underserved, ethnically diverse patient population receiving care at an urban public hospital, yet the sample size did not permit us to investigate the effects of ethnic concordance or language fluency on communication. Indeed, although we believe we reached theoretical saturation in thematic analysis, our sample was small, and our results may not generalize to other types of patients, specialties, or practice settings. Additionally, this was designed as a qualitative study and not intended to produce precise estimates of archetype prevalence or distribution. Finally, we used novel methods to study communication, and all conclusions from our exploratory study should be tested by further research.

This study makes 2 important contributions. First, it illuminates why studies of SDM have led to conflicting results, namely, the rather common discordance between communication behavior and subjective experience. Second, by creating a conceptual synthesis of 2 important components of decision making, summarized in the 4 archetypes of engagement, our study advances the field of patient-physician communication.

In summary, we found that meeting criteria for objective SDM does not ensure that the decision-making process is subjectively collaborative. Relationship dynamics such as trust and power may either influence patterns of communication or mediate the perception of collaboration in the decision-making process. Efforts to enhance patient-physician communication, especially among disadvantaged populations, must include both effective communication behavior and affective relationship dynamics. Future research should determine whether, compared with traditional methods for analyzing decision making, the archetypes emerging from this study predict patient outcomes.

To read or post commentaries in response to this article, see it online at http://www.annfammed.org/cgi/content/full/4/1/54.

Key words: Physician-patient relations; decision making; qualitative research; communication; collaboration

Submitted February 28, 2005; submitted, revised, May 23, 2005; accepted June 6, 2005.

This work was presented in part at the American Public Health Association Annual Meeting, November 2003, San Francisco, Calif; the Society for General Internal Medicine Annual Meeting, May 2004, Chicago, III; the International Conference on Communication and Healthcare, September 2004, Bruges, Belgium; and the Society of Teachers of Family Medicine Annual Spring Conference, Distinguished Research Presentation, May 2005, New Orleans, La.

Funding support: The work for this article was funded primarily by grant 5P01 HS10856 from the Agency for Healthcare Research and Quality for an Excellence Center to Eliminate Ethnic/Racial Disparities (EXCEED) to the University of California, San Francisco, Medical Effectiveness Research Center for Diverse Populations (MERC). Dr Schillinger was supported by grant K23 RR16539. Dr Fernandez was supported by grant K23 RR1018324.

Disclaimer: The sponsors had no role in the design and conduct of the study; collection, management, analysis, or interpretation of the data; or preparation, review, or approval of the manuscript.

Acknowledgments: We gratefully acknowledge our colleagues at the UCSF MERC for their ongoing feedback during the course of this study. We also thank Bernard Lo, MD, for his insightful review of an earlier draft of this manuscript.

\section{References}

1. Zoppi K, Epstein RM. Is communication a skill? Communication behaviors and being in relation. Fam Med. 2002;34:319-324.

2. Elwyn G, Edwards A, Kinnersley P. Shared decision-making in primary care: the neglected second half of the consultation. Br J Gen Pract. 1999;49:477-482.

3. Elwyn G, Edwards A, Kinnersley P, Grol R. Shared decision making and the concept of equipoise: the competences of involving patients in healthcare choices. Br J Gen Pract. 2000;50:892-899.

4. Elwyn G, Edwards $A$, Wensing $M$, et al. Shared decision making: developing the OPTION scale for measuring patient involvement Qual Saf Health Care. 2003;12:93-99.

5. Gwyn R, Elwyn G. When is a shared decision not (quite) a shared decision? Negotiating preferences in a general practice encounter. Soc Sci Med. 1999;49:437-447. 
6. Charles C, Gafni A, Whelan T. Shared decision-making in the medical encounter: what does it mean? (Or it takes at least two to tango). Soc Sci Med. 1997;44:681-692.

7. Charles CA, Whelan T, Gafni A, Willan A, Farrell S. Shared treatment decision making: what does it mean to physicians? J Clin Oncol. 2003;21:932-936.

8. Roter D. The enduring and evolving nature of the patient-physician relationship. Patient Educ Couns. 2000;39:5-15.

9. Murphy J, Chang H, Montgomery JE, Rogers WH, Safran DG. The quality of physician-patient relationships: patients' experiences 1996 1999. J Fam Pract. 2001;50:123-129.

10. Greenfield S, Kaplan S, Ware JE Jr. Expanding patient involvement in care: effects on patient outcomes. Ann Intern Med. 1985;102:520528.

11. Greenfield S, Kaplan SH, Ware JE Jr, Yano EM, Frank HJ. Patients participation in medical care: effects on blood sugar control and quality of life in diabetes. J Gen Intern Med. 1988;3:448-457.

12. Kaplan SH, Gandek B, Greenfield S, Rogers W, Ware JE. Patient and visit characteristics related to physicians' participatory decisionmaking style: results from the Medical Outcomes Study. Med Care. 1995:33:1176-1187.

13. Kaplan SH, Greenfield S, Ware JE Jr. Assessing the effects of physician-patient interactions on the outcomes of chronic disease. Med Care 1989:27:S110-S127.

14. Kaplan SH, Greenfield S, Gandek B, Rogers WH, Ware JE Jr. Characteristics of physicians with participatory decision-making styles. Ann Intern Med. 1996:124:497-504.

15. Xu KT, Borders TF, Arif AA. Ethnic differences in parents' perception of participatory decision-making style of their children's physicians. Med Care. 2004;42:328-335.

16. Golin C, DiMatteo MR, Duan N, Leake B, Gelberg L. Impoverished diabetic patients whose doctors facilitate their participation in medical decision making are more satisfied with their care. J Gen Intern Med. 2002; 17:857-866

17. Mead N, Bower P, Hann M. The impact of general practitioners' patient-centredness on patients' post-consultation satisfaction and enablement. Soc Sci Med. 2002;55:283-299.

18. Davis RE, Dolan G, Thomas $S$, et al. Exploring doctor and patient views about risk communication and shared decision-making in the consultation. Health Expect. 2003;6:198-207.

19. Cooper LA, Roter DL, Johnson RL, et al. Patient-centered communication, ratings of care, and concordance of patient and physician race. Ann Intern Med. 2003;139:907-915.

20. Borkan JM. Mixed methods studies: a foundation for primary care research. Ann Fam Med. 2004:2:4-6.
21. Smedley BD, Stith AY, Nelson AR. Unequal Treatment: Confronting Racial and Ethnic Disparities in Health Care. A Report of the Institute of Medicine. Washington, DC: National Academy Press; 2002.

22. Bloom BS. The thought process of students in discussion. In: French SJ, ed. Accent on Teaching: Experiments in General Education. New York NY: Harper \& Brothers; 1953.

23. Kagan NI, Krathwohl DR, Miller R. Stimulated recall in therapy using video tape: a case study. J Couns Psychol. 1963;10:237-243.

24. Kagan NI, Schauble PG. Affect simulation in interpersonal process recall. J Couns Psychol. 1969;16:309-313.

25. Kagan NI, Kagan H. IPR-a validated model for the 1990s and beyond. Couns Psychol. 1990;18:436-440.

26. Elwyn G, Edwards A, Gwyn R, Grol R. Towards a feasible model for shared decision making: focus group study with general practice registrars. BMJ. 1999;319:753-756.

27. Elwyn G, Edwards A, Mowle S, et al. Measuring the involvement of patients in shared decision-making: a systematic review of instruments. Patient Educ Couns. 2001;43:5-22.

28. Braddock CH 3rd, Edwards KA, Hasenberg NM, Laidley TL, Levinson W. Informed decision making in outpatient practice: time to get back to basics. JAMA. 1999;282:2313-2320.

29. Braddock CH 3rd, Finn SD, Levinson W, Jonsen AR, Pearlman RA. How doctors and patients discuss routine clinical decisions: informed decision making in the outpatient setting. J Gen Intern Med. 1997;12:339-345.

30. NVivo. Version 2.0. Markham, Ontario: QSR International; 2002.

31. Strauss A, Corbin J. Basics of Qualitative Research: Techniques and Procedures for Developing Grounded Theory. 2nd ed. Thousand Oaks, Calif: Sage Publications; 1998.

32. Patton MQ. Qualitative Evaluation Methods. Beverly Hills, Calif: Sage Publications; 1990

33. Patton MQ. Enhancing the quality and credibility of qualitative analysis. Health Serv Res. 1999;34:1189-1208.

34. Stake R. The Art of Case Study Research. Thousand Oaks, Calif: Sage Publications; 1995.

35. Giacomini MK, Cook DJ. Users' guides to the medical literature: XXIII. Qualitative research in health care A. Are the results of the study valid? Evidence-Based Medicine Working Group. JAMA $2000 ; 284: 357-362$

36. Giacomini MK, Cook DJ. Users' guides to the medical literature: XXIII. Qualitative research in health care B. What are the results and how do they help me care for my patients? Evidence-Based Medicine Working Group. JAMA. 2000;284:478-482.

37. Headland TN, Pike KL, Harris M, eds. Emics and Etics: The Insider/Outsider Debate. Newbury Park, Calif: Sage Publications; 1990. 